\title{
Vitamin D Deficiency is Highly Prevalent in Obesity and is Related with BMI and Inflammation
}

Fernández-García JC (1,2), Cardona-Díaz F (2), Cortés Salazar CM (3) Asenjo-Plaza M (4), García-Ruiz MC (4), Varea-Marineto E (4), Banderas-Donaire MJ (4), Alcaide-Torres J (2), Queipo-Ortuño MI (2), Moreno-Indias I(2), Castellano-Castillo D (2), Tinahones F (1,2).

1. Endocrinology Department. Virgen de la Victoria University Hospital. Málaga (Spain), 2 Badolatosa Primary Care Centre. Seville (Spain), 3. Cruz de Humilladero Care Centre. Malaga (Spain), 4. Biomedical Research Laboratory. Endocrinology Department. IBIMA (Malaga)

\section{Objectives}

To study vitamin D deficiency in a cohort of obese males and to evaluate associated clinical and biochemical characteristics.

Methods
- Case-control study which included obese (defined by a body mass
index (BMI) $\geq 30 \mathrm{~kg} / \mathrm{m}^{2}$ ) males.
- Vitamin D deficiency was defined as vitamin D levels $<20 \mathrm{ng} / \mathrm{ml}$.
- Estimation of vitamin D status was determined in serum using a
commercially available enzyme- immuno-assay designed to measure
$25-O H \quad$ Vitamin D concentrations in serum or plasma
(Immundiagnostik,Quantikine, Bensheim, Germany).
- Statistical analysis was performed with SPSS v 15.0 for Windows.

\section{Vitamin D Deficiency (\%) (n-225)}

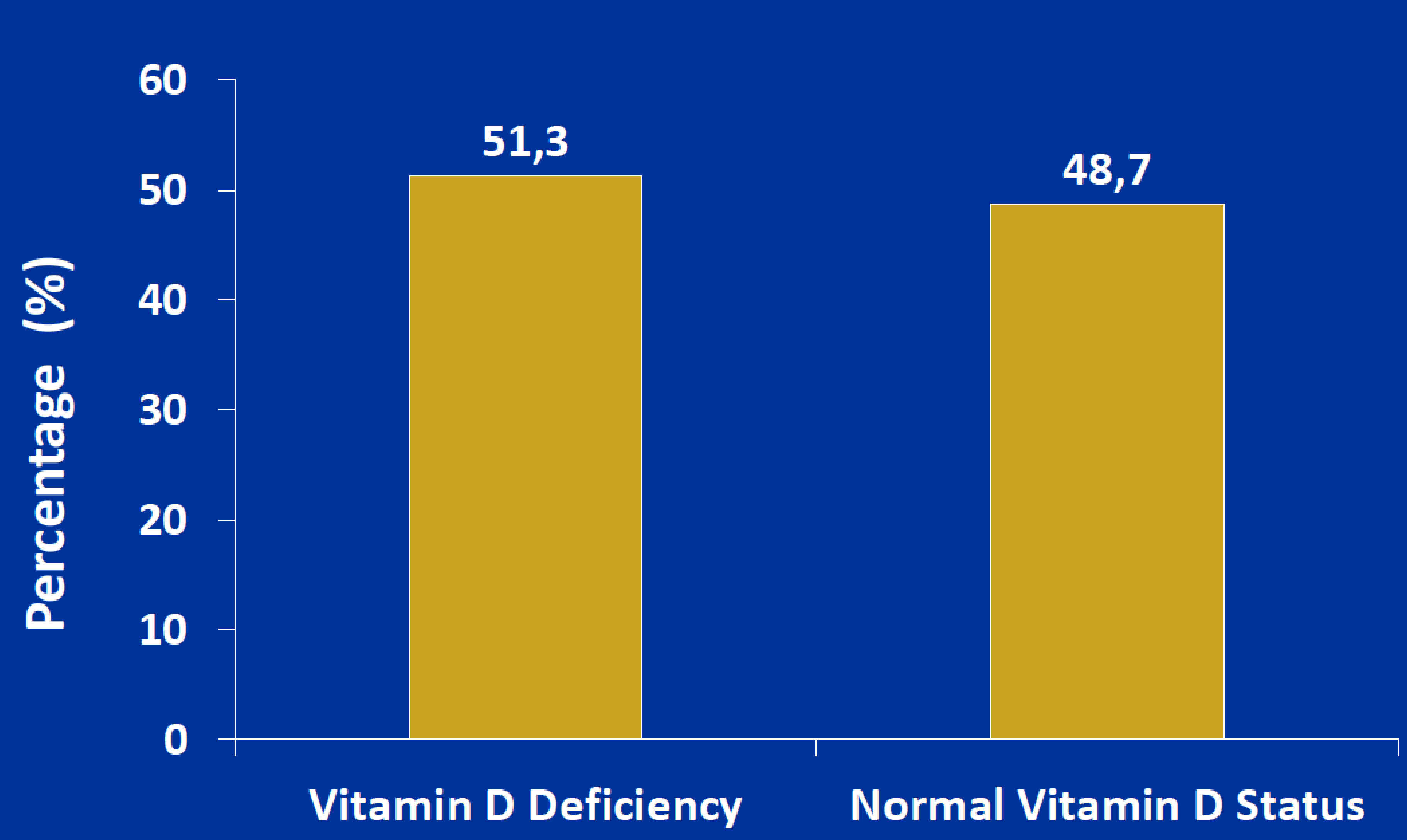

\section{Vitamin D Levels (ng/ml) (n-225)}

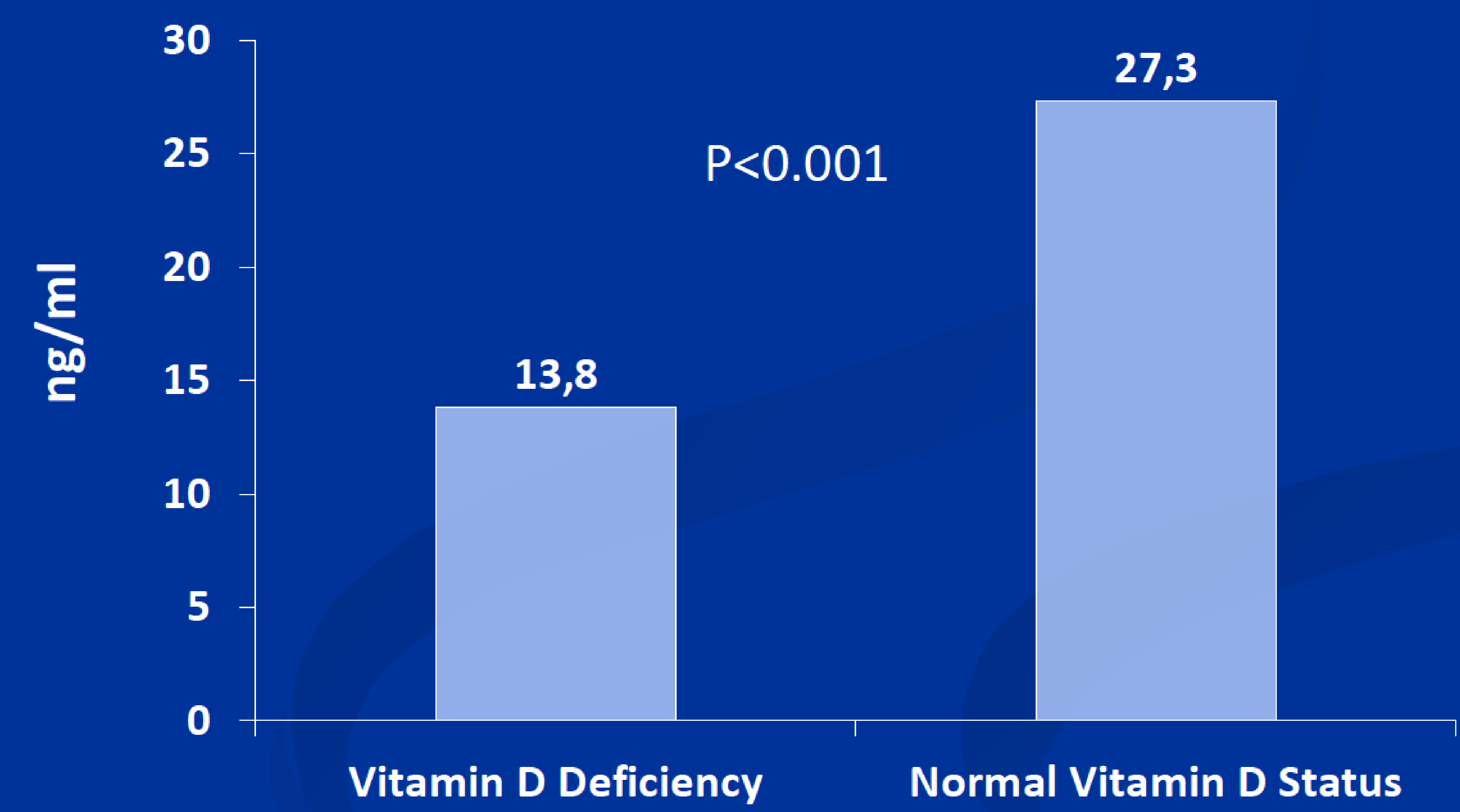

\section{Patients characteristics by Vitamin D status}

\begin{tabular}{|l|c|c|c|}
\hline & Vitamin D Deficiency & Normal Vitamin D Levels & $\mathrm{p}$ \\
\hline Age (years) & $\mathrm{n}-115$ & $\mathrm{n}-110$ & \\
BMI $\left(\mathrm{kg} / \mathrm{m}^{2}\right)$ & $36.0 \pm 7.2$ & $37.7 \pm 7.4$ & 0.1 \\
HOMA-IR & $40.9 \pm 7.1$ & $37.7 \pm 7.8$ & 0.04 \\
PCR $(\mathrm{mg} / \mathrm{L})$ & $5.2 \pm 4.6$ & $4.3 \pm 4.8$ & 0.11 \\
HbA1c $(\%)$ & $7.5 \pm 5.0$ & $5.3 \pm 4.8$ & 0.01 \\
Calcium $(\mathrm{mg} / \mathrm{dl})$ & $5.4 \pm 0.3$ & $5.4 \pm 0.3$ & $\mathrm{~ns}$ \\
PTH $(\mathrm{pg} / \mathrm{ml})$ & $9.0 \pm 0.3$ & $9.1 \pm 0.3$ & $\mathrm{~ns}$ \\
\hline
\end{tabular}

\section{Conclusions}

Vitamin D deficiency affects to approximately $50 \%$ of obese males.

$\Rightarrow$ Patients with Vitamin D deficiency are more obese and have higher PCR levels than patients with normal concentrations of vitamin D. 